\title{
Revista de arte sonoro y cultura aural (3), editada por Samuel Toro y Fernando Godoy, Valparaíso, 2017, 56 p.
}

\author{
Jaime Villanueva \\ Universidad de Valparaíso - Conicyt \\ jaime.villanueva@postgrado.uv.cl
}

Comparto a través de este texto, la experiencia de una lectura. Si atendemos lo elementos centrales de la revista, vemos que el concepto de arte sonoro se nos presenta mediante una discusión sobre la cultura aural, con una bajada hacia lo que los editores identifican como antropología de la escucha. Con ello, es posible reflexionar sobre diferentes tópicos.

Cuando hablamos de arte sonoro, podemos referir a una cierta elaboración estética a partir del sonido. Esto, a veces, introduce la problemática de que la generación y la producción de lenguajes en el arte se restrinjan sólo a quienes puedan hablarlos o entenderlos. La pretensión puede ser que la discusión se extienda, pero, en la práctica, esto suele ser un tanto dificultoso, pues, de suyo, es difícil desarrollar lenguajes -en este caso- artísticos. Ahora bien, cuando hablamos de cultura aural, agregamos otra dimensión relevante, por medio de la cual la revista se posiciona de buena forma ante un público más amplio. Esta dimensión es la de una conciencia auditiva.

La noción de cultura aural, en efecto, refuerza esta conciencia auditiva y de todo cuanto escuchamos. Nosotros, con la visualidad, percibimos desde un ángulo: sólo miramos hacia adelante en 180 grados. Con la audición, en tanto, cubrimos toda una esfera en 360 grados: oímos arriba, abajo, al costado... Nuestra percepción no tiene un centro o un eje. Es ahí donde podemos encontrar muchas cosas y donde, incluso, podemos generar modos interesantes de comprensión del entorno, que devienen finalmente en modos (divergentes) de racionamiento e incluso, a partir de la noción de una antropología de la escucha, podemos encontrar modos epistemológicos para comprender y aproximarnos al entorno.

En la presente edición de Aural, estos tres aspectos (arte sonoro, cultura aural y antropologías de la escucha) se unifican y orientan hacia problemáticas y preocupaciones comunes a un desarrollo de la conciencia auditiva, poniendo en tensión las políticas del conocimiento a las que estamos habituados.

La revista abre con un escrito de Tito Rivas, quien se pregunta qué es lo que vamos a reflexionar y entender cuando emprendamos el camino de esas sonoridades. Apoyado en Michel Foucault respecto a su reflexión sobre la conformación 
de discursos ${ }^{1}$, la que se puede conectar con lo que también señaló Jean-François Lyotard respecto a los metarrelatos (y su dimensión hegemónica propia de la voluntad moderna), el autor apunta a tomar cierta conciencia respecto a la elaboración de lo sonoro como discursos sonoros.

Para Rivas, el sonido también deviene en una forma discursiva; el sonido dice algo. Si tomamos, por ejemplo, una película y analizamos cómo está tratado el sonido en ella, especialmente en una película de Hollywood, vamos a encontrar un discurso del poder expresado en el sonido; discurso que también se expresa en la imagen, el texto, la narrativa, la diégesis en general y en una serie de aspectos más que involucra un tipo de obra cinematográfica.

En esta lectura de la revista Aural, muchas de las reflexiones que nos encontramos se podrían pensar como contra-hegemónicas, pues, al hacer emerger algunas formas de discurso (sonoro), expone una dimensión del poder como implícita en estas formulaciones sonoras. Así, el tono característico de los textos compilados corresponde al de un desafío al poder. Esto no necesariamente se lleva a cabo desde una posición partidaria definida, sino, sencillamente, asumiendo que el discurso sonoro tiene ramificaciones que tensionan las políticas instaladas, ya sea en el ámbito del conocimiento o en términos sociales. Es decir, hay ineludiblemente un aspecto político en la reflexión sobre el sonido, aunque no sea eso lo que se busque por el o la investigador/a o artista sonoro.

Ahí es donde la revista nos ayuda a participar en esa discusión y a comprender parte de las problemáticas y los nudos que se generan en torno a ella.

Un ejemplo de ello lo podemos encontrar en el texto "Antropocentrismo y régimen colonial de la sonoridad" de Mayra Estévez, donde se pregunta "¿a qué suena el capitalismo?". Partiendo de la Conquista en 1492, con la introducción de la pólvora, los caballos, las armas, etc. esta autora plantea que el trauma de la conquista y la colonia es también sonoro. Está ligado a una violencia política que podríamos examinar desde la perspectiva del genocidio.

En ese sentido, la antropología de la escucha nos podría orientar para entender otros acontecimientos. Por ejemplo, se han hecho ejercicios en relación al bombardeo a la Moneda y en ellos también hay una identificación característica, que es la de los sonidos del terror, de la violencia del poder.

Por otro lado, el ensayo de Leandro Pisano titulado "El pasaje del tiempo" reflexiona respecto a la generación de herramientas críticas que permitan valorar los flujos del espacio-tiempo y cómo eso se puede ir conservando o perdiendo, según inscripción en un territorio. La preocupación presente en el texto de Pisano tiene

\footnotetext{
${ }^{1}$ En este punto el autor se apoya en la noción de antropología del saber a partir de M. Foucault.
} 
que ver con alguien que se sitúa en una zona rural y atiende a la escucha, pero lo problematiza con el hecho que, desde una percepción urbana, se enfrenta a un diseño estático y que en algunos casos conduce a la exotización de lo rural, comprendido como lo pintoresco, lo folclórico o, cuando mucho, lo neo-folclórico. ¿Por qué ocurre esto? Porque también hay ahí un diseño para entender lo rural. La reflexión de Pisano insiste sobre cómo se diseña este sonido rural y cómo podemos atenderlo. Podríamos ir descubriendo sonidos que ya no existen, porque los modos de producirlos ya no existen, (re)construyendo, a partir de vestigios sonoros, una ruta discursiva sonora en el espacio rural. ¿Cómo se construye un campo semántico a partir de vestigios rurales? Esto motiva un punto sobre si es el campo o la ciudad, quien crea el signo sonoro. ¿Quién crea lo rural? ¿Lo hace la ciudad misma? ¿Se puede hacer desde dentro, si el mismo sujeto situado atiende o no?

El texto de Pisano entra en diálogo con el de Luis Costa, titulado "El sonido gordiano", porque también se plantea en relación a volver al pueblo rural. Ya no se trata de un autor italiano, sino de un autor portugués, pero también se plantea esto de volver a algo menos moderno, y lo hace entendiendo la mirada de una ciudad metropolitana; no como un retorno al paraíso perdido, sino a tomar cosas que han ido quedando fuera del discurso (sonoro), de la cadena de significantes que se emplazan -por la razón que sea- en una discusión que se abre políticamente y puede darse en diversos espacios.

Luis Costa señala que "una grabación es un sistema de decisiones", lo que resulta ciertamente sugerente, tomando en cuenta que ya eso se decía de la fotografía, cuando la fotografía tenía el peso del testimonio. Lo que ya no es tan claro, pues también a través de la fotografía podemos decir lo que queramos dependiendo de qué enfoquemos, cómo lo enfoquemos, en el ángulo, a qué distancia, etc. más aún si contemplamos que con el paso a lo digital podemos elaborar nuestras propias imágenes. Con la grabación sonora sucede algo semejante. En esta experiencia, la de alguien que va y se sitúa en un lugar, se intentan tomar elementos de ese espacio para llevarlos después a otro, ya sea al muestrario, la universidad, la televisión, el documental, etc., deviniendo en un proceso del que también es necesario tener autoconciencia. Luis Costa indica algo interesante con respecto a quién hace un registro sonoro, ya sea desde una perspectiva turística, aural o artístico-estética, y tiene que ver con un escuchador "in between". Esto conlleva una percepción y una construcción individual que resulta profundamente inestable, corriéndose constantemente el riesgo del error. Pero no se trata aquí de una declaración meramente performativa, sino de algo que se intenta poner en el sistema de decisiones. ¿Qué quiere decirse aquí, entonces, con el "in between" inestable, propenso al error? Este sistema de decisiones no puede establecerse necesariamente como el discurso, sino como una posible lectura del fenómeno y, por 
sobre todo, poniendo cuidado en que este investigador, por llamarlo así, se transforme en un generador de nuevos discursos oficiales. Si no se es consciente de esto, el investigador podrá ser un replicador de los relatos hegemónicos, quizás, incluso, sin tomar conciencia de ello.

"Orquesta, tropa y perros", de José Pérez de Arce, es otro texto bastante interesante de la revista, por su frescura. Es una reflexión sobre las orquestas como mecanismo de desarrollo y de transmisión de la cultura. Señala que las inversiones estatales que se hacen, por ejemplo, en orquestas juveniles y formación de audiencias apuntan a una forma de educación sonora. En este sentido, la orquesta es una apuesta de construcción discursiva que expresa una voluntad moderna desde lo formativo, es decir, que apunta a enseñarles, a los que no saben, algo para aprender y, con ello, ilustrar. Se trata, en esta perspectiva, de mostrar la cultura de la música también como un ejercicio racional, intelectual, académico y propio del saber. Por otro lado, Pérez de Arce apunta al tema de las tropas, que tienen que ver más con elementos de los pueblos originarios del norte-o de folclor, en algunos casos-, como en las agrupaciones de Lakitas, por ejemplo, que generan su sonido, su cultura y una ecología cultural asociados más al territorio y su idenidad, a diferencia de la orquesta, que tiene un carácter transnacional.

Luego, el autor aborda el sonido de los perros, presentando una reflexión que parece decirnos: "dejad que los perros ladren". Hay una aproximación al sonido con una mirada más bien naturalista, en tanto lo presenta como un tema evolutivo de un "sistema" sonoro de los ladridos de los perros en la ciudad. Sin embargo, no deja de ser interesante contrastar a los perros con una orquesta y su sonido organizado con esta especie de "banda" de ladridos de perros como sonido devenido y tonalizado. Probablemente, esto último lo construya la percepción del auditor cuando pone atención a los ladridos que de noche hacen los perros en un barrio, una calle, un predio, etc. Si emerge melodía o armonía, un eje tonal; incluso, si lo quiere oír como música o sólo como sonidos de un proceso evolutivo, habría que reflexionarlo en perspectiva respecto a si es homologable o contrastable con las orquestas y las tropas y con ello pensar el contraste de estos modos de organización sonora.

Ximena Alarcón, en su texto "Bajo la tierra escucha porosa de la modernidad", alude a "la escucha de la contradicción" en el metro de México el que representa un aspecto de una voluntad de modernidad que no consigue serlo del todo. Nos encontramos con sonidos de metales, tecnológicos, puertas que abren, voces automatizadas, etc., pero también con mascotas que van en jaulas y gritos de vendedores precarizados, entre otros. Es un sonido poroso que atraviesa la ciudad como un murmullo, arrastrando una pre-modernidad que, no por subterránea, se niega a dejar de sonar. 
Probablemente, uno de los principales aportes sobre antropología de la escucha que nos dejan los textos compilados en Aural n. 3, dicen relación con que la reflexión sobre el sonido y los signos sonoros, así como su sistematización teóricopráctica, posiblemente interdisciplinaria, permite encontrar elementos nuevos donde no los estamos viendo, pero sí podemos estar escuchándolos. Además de las políticas del conocimiento puestas en juego en la idea de una conciencia auditiva como síntesis y articulación del arte sonoro, la cultura aural y la antropología de la escucha, bien pueden representar la apertura a aspectos epistemológicos y estéticos nuevos, para la comprensión, la lectura y el análisis de entornos que tienen sus propias historias y proyecciones y que todavía nos son ampliamente desconocidos. 